\title{
Comparative Effects of Three Varieties of Rice Staple Water as A Probiotic and Anti-Microbial Agent
}

\author{
Fauzia Ahmed ${ }^{1}$, Kalaiyarasi.L ${ }^{2}$, Aishwarya Ravi ${ }^{3}$ \\ 1, 2, 3 (PG \&Research Department of Zoology, JBAS college for Women/Madras University, India)
}

\begin{abstract}
In the present study a preliminary attempt has been made to analyse the presence of probiotic activity in rice staple water and also to prove the importance of rice staple water as an effective probiotic by comparing three varieties of rice staple water namely brown rice, raw rice and parboiled rice as a sample. Three varieties of rice from which the staple water was taken and the analysis was carried out using culture technique, biochemical analysis and confirmatory tests. From this study, two commonly known lactose fermenting probiotic organisms were obtained namely as lactobacillus and lacto coccus. Further, the samples were subjected to evaluate the inhibitory effect of the probiotics against pathogenic bacteria. Out of the result obtained, sample 1 (Brown rice) was found to be more potent than the other samples having anti-microbial activity.
\end{abstract}

Keywords:Anti-microbial activity, Lactobacillus, Lacto coccus, Probiotic, Rice staple water.

\section{Introduction}

From time immemorial rice has been the staple food of India and popular in Asia. Rice (Oryza sativa L.) attains second place among cereal crop, both for acreage and production in the world $[1,2]$. It is an important cereal next to wheat for domestic demands and it can be an effective weapon for increasing the foreign exchange however, its yield is low in Pakistan as compared to other countries [3]. Generally rice contains 4 to $10 \%$ crude fibre; however, this changes with the cultivation, variety, environment etc., [4].

Rice is one of the most important crops in the world [5, 6] along with wheat and maize [7]. Rice is the staple food for a large population of the world's human population and has been a source of food for people from 2500 B.C. Rice production was initiated in China and spread to countries such as India and Sri Lanka [8]. Rice is important due to its high digestibility and biological value [9]. The chemical and nutritional quality of rice grain varies significantly and the major factors that contribute to the differences are genetic factors, environmental influences, fertilizer treatments, degree of milling, storage conditions, cultivation processes, thickness of anatomical layers, size and shape of grains, and the resistance of grains to breakage and abrasion $[10,11]$. The nutritional quality of rice can be further differentiated based on the milling conditions such as, processing methods and the machines used for processing [11].

\subsection{Rice varieties}

Rice is basically in three forms: brown, red and white rice. Brown rice is produced by dehusking the hull. This causes the least damage to the nutritional quality of the rice and prevents excessive loss of nutrients that can arise with further milling. When brown rice is further processed to remove the bran and most of the germ layer, the outcome is white rice. At this point, however, cereal is known as unpolished rice, and it takes further milling or polishing to produce polished rice. This is commonly known as white rice. Thus, rice is ground into several milling grades to obtain the many different types of rice flours and grains. This includes brown rice (hull removed), unpolished red rice (hull bran and most of germ removed) and polished rice (aleurone layer removed from unpolished rice) [12]. Un-milled rice has more protein and fibre than milled or polished rice and can be considered as more nutritious [13].

Brown rice consists of the outer layers (pericarp, seed-coat), and the nucleus (bran), and the germ or embryo; and the endosperm. The endosperm consists of the aleuronic layer. The aleuronic layer encloses the embryo. Pigment is confirmed to the pericarp [14] which gives colour of brown rice.

Rice with red bran layers is called red rice. Though the colour is confirmed to the bran layer, a tinge of red remains even after a high degree of milling. The colour of the bran ranges from light to dark red. The bran layer contains polyphenol and anthocyanin and possesses antioxidant properties. The inner portion of red and white rices is alike and white. The zinc and iron content of red rices is 2-3 times higher than that of white rice [15]. American scientists have reported similar high iron content in the Chinese red varieties 'Bloody Sticky' and 'Dragon Eyeball' [16].

Milled rice has had the hulls and bran removed. It also called white rice or polished rice [17]. Most milled rice sold into the domestic market has been milled very hard and has the broken content removed to 
below $4 \%$. Less expensive rice sold to export markets may be milled to a lesser degree and may have higher percentage of broken kernels.

\subsection{Probiotics}

Probiotics are defined as the live micro organisms which are a dietary supplement that possess many beneficial effects to the host by their activities in the human gut $[18,19]$. They are able to survive in the presence of the bile acids in the human gut and able to form colonies in the gastrointestinal tract without harming the host [19]. Although many few strains of micro organisms have probiotic characteristics [20], they are mainly Lactobacillus and Bifidobacterium.

Food that selectively stimulates the growth of these organisms in the human gut is known as probiotic [21]. Probiotics either naturally occur in the food or can be specific supplements. Probiotics are mainly dietary fibres [20]. The intake of a probiotic can increase a specific probiotic or a limited number of beneficial bacteria commensal in the colon [22] and can change the composition of the micro organisms in gut to a healthy flora $[23,24]$. Probiotics can induce luminal or systemic effects that are beneficial to the host's health. Any food that is a probiotic should be neither hydrolysed nor absorbed in the upper part of the gastrointestinal tract. A combination of probiotic micro organisms and probiotic carbohydrates is called as a symbiotic food.

Foods that are consumed by endogenous colonic bacteria in the colon are known as colonic food. These foods indirectly provide the host with energy, methanolic substrates and essential micronutrients. Non digestible carbohydrates (oligosaccharides and polysaccharides), some peptides, proteins and certain lipids (both ethers and esters) are not absorbed in the upper part of the gastro intestinal tract or hydrolysed by the human digestive enzymes. These foods can be considered as candidates for probiotics [22]. Non digestive carbohydrates (resistant starch, non-starch polysaccharides, plant cell wall polysaccharides, hemicellulose, pectin, gums and non digestible oligosaccharides) [25] can all be classified as colonic foods.

According to the current data available on the probiotics as noted in 2002 by Food and Agriculture Organization (FAO) and the World Health Organisation (WHO), probiotic micro organisms that are most effective on health of human when consumed in adequate amounts. However, in this statement, "adequate amount" of probiotics or the number of liver microbes required has not been defined yet. Metabolically active bacteria are useful in the human gut only if the number of micro organisms per gram of food is in excess of $10^{6}$ at the time of consumption.

The importance of probiotics are as managing lactose intolerance, prevention of colon cancer, lowering cholesterol, lowering blood pressure, improving immune function and preventing infections, reducing antibioticassociated diarrhoea and inflammation, etc,.

\section{Materials And Methods}

Three rice varieties were selected for the study based on their availability and their popularity in India. Brown rice (Palakkadu Matta), Ponni rice (Raw rice) and Puzhungal rice (Parboiled rice) were mostly used for the preparation of several processed rice products.

\section{1 preparation of Sample}

The above mentioned rice varieties were washed well with water. The staple water was prepared by taking 200 grams of rice in $600 \mathrm{ml}$ of water in a vessel and it was cooked. The water was them drained out and taken in a sterile glass bottle which was autoclaved 10 minutes before draining the staple water. The sample was then taken to the laboratory within 2 hours for further studies and labelled as sample 1, sample 2 and sample 3 .

\subsection{Serial Dilution}

$25 \mathrm{ml}$ of the sample was poured into $225 \mathrm{ml}$ of Ringer Martin solution. It was mixed well which gave the dilution of $10^{-1}$. From this dilution $10 \mathrm{ml}$ of the sample was poured into $90 \mathrm{ml}$ of Ringer Martin solution. It was mixed well and gave the dilution $10^{-2}$. From this $1 \mathrm{ml}$ of sample was taken and transferred into $9 \mathrm{ml}$ of Ringer Martin solution and marked as $10^{-3}$. $1 \mathrm{ml}$ of sample was taken from $10^{-3}$ dilution and transferred in another $9 \mathrm{ml}$ of Ringer Martin solution. It was marked as $10^{-4}$ dilution. From this $1 \mathrm{ml}$ of sample was poured into $9 \mathrm{ml}$ of Ringer Martin solution and marked as $10^{-5}$ dilution. $1 \mathrm{ml}$ of sample was taken and diluted with $9 \mathrm{ml}$ of solution which was autoclaved and marked as $10^{-6}$ dilution. From $10^{-6}$ dilution $1 \mathrm{ml}$ of sample was taken and transferred into $9 \mathrm{ml}$ of the solution. It was marked as $10^{-7}$ dilution. Finally, from $10^{-7}$ dilution $1 \mathrm{ml}$ of sample was taken out and discarded.

The main purpose of Serial Dilution is to isolate the population of the microbes in order to pick up the colonies using Agar medium. 


\subsection{Grams Staining}

In a glass slide the smear of the organism were made using an inoculation loops. It was air dried and then heat fixed. The smear was first treated with the basic dye, methyl violet solution, so that it covers the whole smear and appears violet. It was allowed to act for 1 minute and then rinsed with distilled water. The smear was then treated with Gram's iodine solution and allowed to react for 30 seconds to 1 minute and rinsed with distilled water. It forms a complex with methyl violet inside the cell. The smear was then decolorized with $95 \%$ ethanol by holding the slide in a slanting position. The alcohol was added drop by drop with the help of a dropping bottle on the slide so that the alcohol runs over the smear and decolourizes it. The decolourization may take $30 \mathrm{sec}$ to $1 \mathrm{~min}$ and immediately washed with distilled water. During the process some bacteria loose the methyl-iodine complex (MV-I), where as some bacteria retain the MV-I complex. The smear was then covered with safranine and allowed to act for $1 \mathrm{~min}$. It was then rinsed with distilled water. At this stage, the organisms which have lost the MV-I complex take up the pink dye and appear pink. The ones which did not lose MV-I complex remained violet. It was then air dried and examined under the microscope with oil immersion objective.

\subsection{Motility Test}

A grease free cavity slide and a grease free cover slip was taken. 4 corners of the cover slip were covered with Vaseline gel. A drop of distilled water was placed on the cover slip. Then the colony was inoculated with a circular loop on the drop of water placed on the cover slip. The slide was then reversed. In between the gap the motility of the organisms was seen. The margin of the cover slip was viewed under microscope with 40x objective.

\subsection{Catalase Test}

Pure growth of the organisms was transferred from the agar to a clean slide with a loop or glass rod. A drop of $3 \%$ hydrogen peroxide was added to the growth and the result was observed.

\subsection{Oxidase Test}

With the help of an inoculation loop a colony was picked up from the pure culture plate. It was rubbed over the oxidase reagent paper. Development of purple colour indicates the result.

\subsection{Biochemical Tests \\ 2.7.1 Citrate Test}

A small quantity of the pure growth was transferred on nutrient agar and made into a streak on the Simmon's Citrate agar using an inoculation loop. The tubes were placed in slanting position and allowed to solidify. It was incubated at $37^{\circ} \mathrm{C}$ for 24 hours. The result was viewed by change in colour.

\subsubsection{Indole Test}

A small quantity of the pure growth was transferred on nutrient agar into the peptone water using an inoculation loop. The contents were makes by gently rolling the tubes between the palms. It was incubated at $37^{\circ} \mathrm{C}$ for 24 hours. The result was viewed by adding few drops of kovac's reagent.

\subsubsection{Methyl Red Test}

MR broth was prepared and sterilized using in an autoclave at $121^{\circ} \mathrm{C}$ for $15 \mathrm{~min}$ in $15 \mathrm{Lbs}$. The test tubes with broth were inoculated with the test culture. It was incubated at $37^{\circ} \mathrm{C}$ for $24 \mathrm{hrs}$. The results were viewed by adding MR reagent and were thoroughly mixed.

\subsubsection{Triple Sugar Iron Test}

The ingredients were mixed well and the agar was dissolved by boiling. The $\mathrm{pH}$ was the checked. It was distributed in $3-4 \mathrm{ml}$ quantities in $12 \times 100 \mathrm{~mm}$ test tubes. It was then autoclaved at $121^{\circ} \mathrm{C}$ for $15 \mathrm{~min}$ in 15 lbs; and allowed to set in such a way that about 1 inch butt and a slope were obtained. The organisms was then picked from the top of a single colon from primary isolation plate or from pure growth with a straight wire, and inoculated by stabbing down the centre of agar butt carefully. The inoculating wire was carefully at $37^{\circ} \mathrm{C}$ and the result was read after 18-24 hrs of incubation.

\subsection{Sugar Fermentation Test}

$5 \mathrm{ml}$ of peptone water was taken in a test tube to which $1 \%$ sugar solution (Glucose and Lactose) was added. To it Durhan's tube was placed in inverted position. The test tube was autoclaved at $121^{\circ} \mathrm{C}$ for $15 \mathrm{~min}$ in $15 \mathrm{lbs}$ and was cooled. The test culture was inoculated into Durhan's tube and incubated at $37^{\circ} \mathrm{C}$ for $48 \mathrm{hrs}$. Based on the presence of turbidity and gas production the results were confirmed. 


\subsection{Aerobic and Anaerobic Test}

0.56 grams of MRS agar was dissolved in $10 \mathrm{ml}$ of distilled water. It was cotton plugged and autoclaved at $121^{\circ} \mathrm{C}$ for $15 \mathrm{~min}$ in $15 \mathrm{lbs}$.

The agar was poured in 2 petri plates, one for aerobic growth and the other for the anaerobic growth of the organisms. The test organisms were taken from the agar's land and were streaked on the MRS agar plates. The aerobic plate was incubated at $48^{\circ} \mathrm{C}$ and the anaerobic plate was incubated at $72^{\circ} \mathrm{C}$ for $48 \mathrm{hrs}$ in an aerobic chamber (this slows down the growth). The colony morphology was then identified.

\subsection{Nacl Tolerance Test}

1 gram of $5 \%$ of sodium Chloride salt was mixed with $5 \mathrm{ml}$ of MRS broth in a test tube. In another tube $5 \mathrm{ml}$ of MRS broth without salt was taken. With a circular loop the test cultures were inoculated into the broth (with and without salt) and it was incubated at $37^{\circ} \mathrm{C}$ for $48 \mathrm{hrs}$.

\subsection{Bile Tolerance Test}

1 gram of $2 \%$ Bile salt was mixed with $5 \mathrm{ml}$ of MRS broth in a test tube. In another tube $5 \mathrm{ml}$ of MRS broth without Bile salt was taken. With a circular loop the test cultures were inoculated into the broth (with and with out bile) and it was incubated at $37^{\circ} \mathrm{C}$ for $48 \mathrm{hrs}$.

\subsection{PH Tolerance Test}

The test cultures were grown in $5 \mathrm{ml}$ of MRS broth at $37^{\circ} \mathrm{C}$ for $48 \mathrm{hrs}$. The cultures were centrifuged at $8000 \mathrm{rpm}$ for $10 \mathrm{~min}$ at $4^{\circ} \mathrm{C}$. The pellets were washed twice in sterile phosphate-buffered saline (PBS), with $\mathrm{pH}$ 7 and resuspended (1:100) in PBS to achieve a cell density of $1 \times 10^{12}$ cells $/ \mathrm{ml}$. The cultures were analysed for $\mathrm{pH}$ $1, \mathrm{pH} 2$ and $\mathrm{pH} 3$.

To $9.9 \mathrm{ml}$ of PBS at $\mathrm{pH} 1 ; 0.1 \mathrm{ml}$ from $5 \mathrm{ml}$ PBS was added. This procedure was repeated for every 1 hour up to 3 hours to record the growth of the colony. Similarly for $\mathrm{pH} 2$ and $\mathrm{pH} 3$, the same procedure was carried out to record the growth.

\subsection{Antimicrobial Test}

Muller-Hinton agar (MHA) was used as the medium for bacterial growth. MHA was weighed for 7.6 grams and taken in a clean conical flask. It was diluted with $200 \mathrm{ml}$ of distilled water and then plugged using absorbent cotton. It was autoclaved at $121^{\circ} \mathrm{C}$ for $15 \mathrm{~min}$ in $15 \mathrm{lbs}$ and then cooled.

Sterile petri plates were used for the preparation. The prepared MHA was poured into plates and allowed to solidify. The incubated pathogenic micro organisms (Escherichia coli, Salmonella typhi, Staphylococcus aureus, Listeria, Shigella, Enterobactor, Klebsiella, Micrococcus, Proteus bulgaris, Bacillus cereus) were swabbed on the surface of agar using sterile cotton swab. The well was cut using a well borer. One drop from the test culture broth was added into the well. The plates were incubated at $37^{\circ} \mathrm{C}$ for 24 hrs. The growth of the organisms was observed by the formation of the zone and the diameter was measured in millimetres.

\section{Results}

From the present study that was carried out to evaluate the efficacy of 3 varieties of staple water as a probiotic and antimicrobial agent the following results were deduced. Rice staple water was found to contain two important probiotic organisms namely, Lactobacillus and Lacto coccus. These two important bacteria as we all know are the beneficial bacteria that are found invading the micro population of our intestine and the probiotic tests that were carried out confirmed it. The existences of two beneficial micro organisms were confirmed by conducting the following tests.

Characterisation of probiotic organisms were confirmed that the gram staining test of sample 1 and sample 3 showed purple coloured, non-sporulating, rod shaped colonies. In sample 2, purple coloured, nonsporulating, circular colonies were formed. The motility test of all 3 samples performed that the organisms might be a non-motile. Due to the organisms showed growth on aerobic and anaerobic plate, it might be confirmed that they could survive in both condition (Table1).

From the confirmatory tests done for probiotics like $\mathrm{pH}$, bile tolerance, Nacl tolerance and sugar fermentation tests, it was deduced that the probiotic organisms like Lactobacillus and Lacto coccus survived in extreme acidic $\mathrm{pH}$ as observed in our results. This might be due to the fact that most of the probiotic organisms found in the digestive juices of intestine service in an acidic $\mathrm{pH}$ due to the secretion of Hcl (Hydro chloric acid) which is a week acid of $\mathrm{pH} \mathrm{1-2} \mathrm{up} \mathrm{to} \mathrm{4-5.} \mathrm{Similarly} \mathrm{they} \mathrm{were} \mathrm{found} \mathrm{to} \mathrm{be} \mathrm{tolerant} \mathrm{to} \mathrm{the} \mathrm{bitter} \mathrm{bile} \mathrm{salts} \mathrm{because}$ the bile juice secreted by the gall bladder also serves as a store house for the probiotic organisms and hence it might be due to that. The same could be attributed to the Sodium Chloride tolerance and sugar fermentation tests, because sugar fermentation test serves as an indicator for the amount of Lactose that is digested by the 
probiotic organism, similarly Sodium Chloride test helps in analysing the growth of the probiotic at a particular level of Nacl when compared with a control (Table1, 2 and Fig.1).

Further, the presence of two probiotic organisms were analysed with anti-microbial activity by subjecting 10 bacterial strains to these probiotic cultures and the inhibitory zones were recorded (Table 3 and Fig. 2, 3, 4).

Out of the 3 samples were tested, sample 1 namely as Brown Rice (Palakkadu Matta) was found to offer higher amount of microbial resistance and was more effective as a probiotic also. Among the micro organisms that were tested for anti-microbial effect of these probiotic samples Staphylococcus bacteria showed the greatest inhibitory zone.

\section{Figures And Tables}

Table 2: Effect of $\mathrm{pH}$ on the presence of micro organism based on probiotic used

\begin{tabular}{|c|c|c|c|c|}
\hline Samples & $\mathbf{P H}$ & $\mathbf{1}^{\text {st }} \mathbf{h o u r}$ & $\mathbf{2}^{\text {nd }} \mathbf{h o u r}$ & $\mathbf{3}^{\text {rd }} \mathbf{h o u r}$ \\
\hline \multirow{3}{*}{ Sample 1 } & 1 & 8 organisms & 3 organisms & Nil \\
\cline { 2 - 5 } & 2 & 23 organisms & 13 organisms & Nil \\
\cline { 2 - 5 } & 3 & 36 organisms & 21 organisms & organisms \\
\hline \multirow{3}{*}{ Sample 2 } & 1 & 5 organisms & Nil & Nil \\
\cline { 2 - 5 } & 2 & 18 organisms & 10 organisms & 5 organisms \\
\cline { 2 - 5 } & 3 & 30 organisms & 19 organisms & Nil \\
\hline Sample 3 & 1 & Nil & Nil & Nil \\
\cline { 2 - 5 } & 2 & Nil & Nil & Nil \\
\cline { 2 - 5 } & 3 & 4 organisms & & \\
\hline
\end{tabular}

Table 1: Characterization test for micro organism using the Rice staple water

\begin{tabular}{|c|c|c|c|c|}
\hline Test performed & Name of the Test & $\begin{array}{c}\text { Sample 1 } \\
\text { (Brown rice) }\end{array}$ & $\begin{array}{c}\text { Sample } 2 \\
\text { (Raw rice) }\end{array}$ & $\begin{array}{c}\text { Sample } 3 \\
\text { (Par Boiled rice) }\end{array}$ \\
\hline \multirow[t]{4}{*}{ Characterisation Tests } & Grams staining & + & + & + \\
\hline & Motility test & non motile & non motile & non motile \\
\hline & Catalase test & - & - & - \\
\hline & Oxidase test & - & - & - \\
\hline \multirow[t]{6}{*}{ Biochemical Tests } & Citrate test & - & - & - \\
\hline & Indole test & - & - & - \\
\hline & Methyl Red test & + & + & + \\
\hline & Triple sugar iron test & alkaline & Alkaline & Alkaline \\
\hline & $\mathrm{H}_{2} \mathrm{~S}$ & - & - & - \\
\hline & Gas & - & - & - \\
\hline \multirow{5}{*}{$\begin{array}{l}\text { Lactic acid bacteria } \\
\text { confirmatory Tests }\end{array}$} & Glucose & + & + & + \\
\hline & Lactose & + & + & + \\
\hline & Aerobic test & + & + & + \\
\hline & Anaerobic test & + & + & - \\
\hline & Nacl tolerant test & + & + & + \\
\hline $\begin{array}{c}\text { Probiotic confirmatory } \\
\text { Tests }\end{array}$ & Bile salt tolerant test & + & + & + \\
\hline
\end{tabular}

Table 3: Anti-bacterial activity of Rice staple water

\begin{tabular}{|c|c|c|c|}
\hline Pathogenic organisms & $\begin{array}{c}\text { Sample 1 } \\
\text { (inhibitory zone in mm) }\end{array}$ & $\begin{array}{c}\text { Sample 2 } \\
\text { (inhibitory zone in mm) }\end{array}$ & $\begin{array}{c}\text { Sample 3 } \\
\text { (inhibitory zone in mm) }\end{array}$ \\
\hline Bacillus sp & $+(29 \mathrm{~mm})$ & $+(25 \mathrm{~mm})$ & - \\
\hline Enterobactor sp & $+(44 \mathrm{~mm})$ & - & - \\
\hline Escherichia sp & $+(32 \mathrm{~mm})$ & - & - \\
\hline Klebsiella sp & $+(23 \mathrm{~mm})$ & - & - \\
\hline Listeria sp & $+(25 \mathrm{~mm})$ & - & - \\
\hline Micrococcus sp & $+(44 \mathrm{~mm})$ & - & - \\
\hline Proteus sp & $+(26 \mathrm{~mm})$ & $+(12 \mathrm{~mm})$ & - \\
\hline Salmonella sp & $+(19 \mathrm{~mm})$ & - & - \\
\hline Shigella sp & $+(17 \mathrm{~mm})$ & $+(35 \mathrm{~mm})$ & - \\
\hline
\end{tabular}




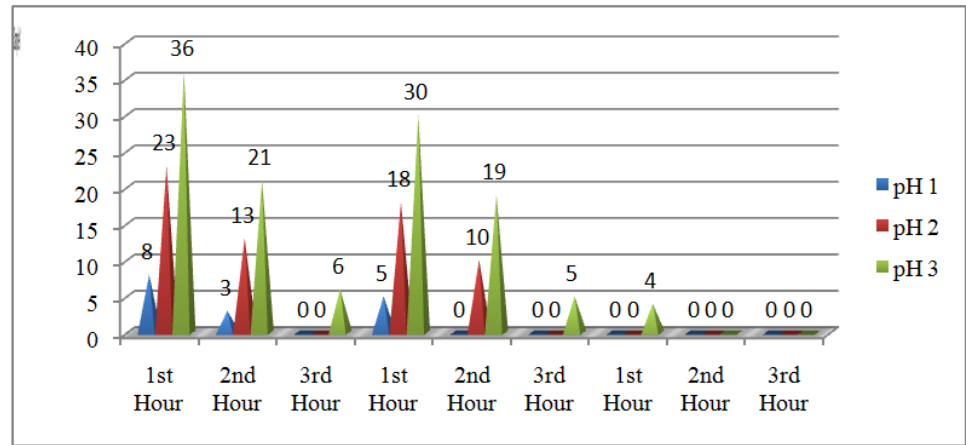

Figure 1: PH Tolerance of Probiotics in 3 varieties of Rice staple water.

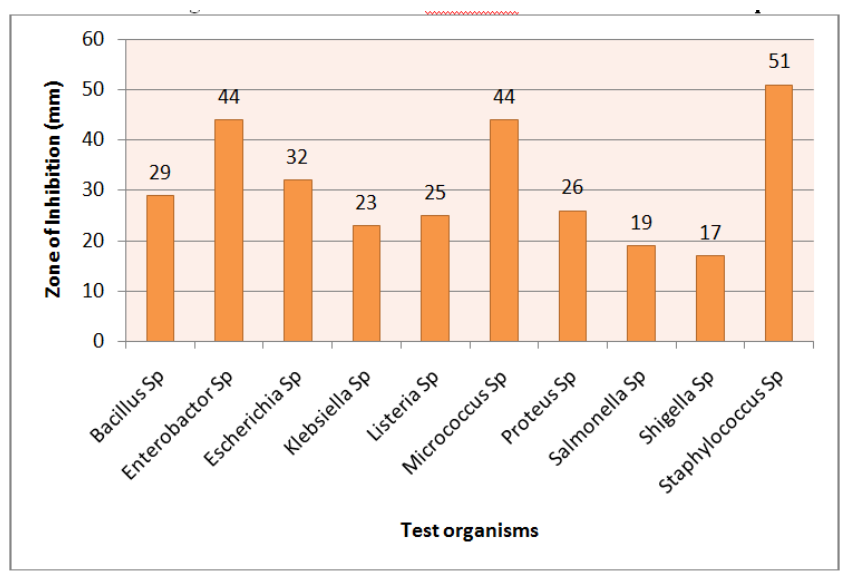

Figure 2: Anti-microbial activity of Brown rice (Sample 1) staple water containing probiotic Lactobacillus Sp inhibiting pathogenic micro organisms.

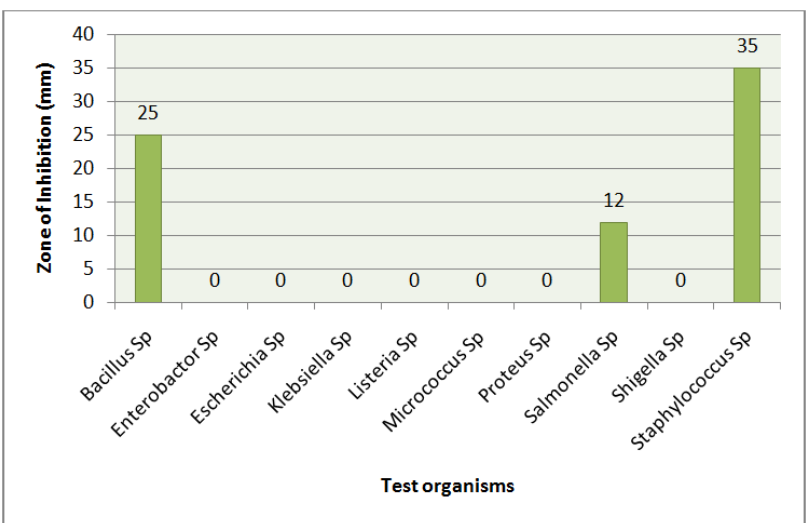

Figure 3: Anti-microbial activity of raw rice (Sample 2) staple water containing probiotic Lacto coccus Sp inhibiting pathogenic micro organisms.

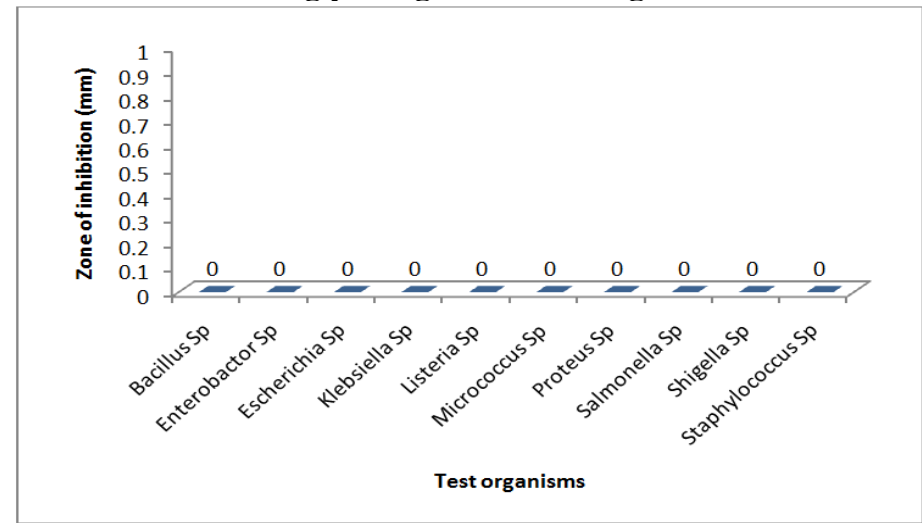

Figure 4: Anti-microbial activity of Par Boiled rice (Sample 3) staple water against pathogenic micro organisms. 


\section{Conclusion}

In the present study the efficiency of the rice varieties available in Tamilnadu and other parts of South India were studied for their probiotic properties, their biochemical nature and their anti-microbial activities. Among the samples analysed, brown rice offered the highest probiotic effect and emerged as the most potent anti-microbial agent. From this we can calculate that traditionally grown cereals have the highest potential and offer more health benefits to the society. This might be of use to the parched public of Chennai city because vary often rice staple water is discarded, if this is put to greater use it might emerge as a potential traditional beverage in the years to come.

\section{References}

[1] FAO- Food and Agricultural organisation, Report on Crop prospects and food situation, Global cereal supply and demand brief, 2009.

[2] S. Hafner, Trends in maize, rice and wheat yields for 188 nations over the past 40 years; a prevalence of linea growth, Agricultural Ecosystems and Environment 97 (1-3), 2003, 273-283.

[3] M. Khalid, F.M. Chaudhry, H. Abid, Effect of different levels of NFK on the yield and quality of Rice C.V. IK- 6", Journal of Research Science, 14 (1), 2003,11-15.

[4] Anonymous, Rice, Middle Cast is the global import, exports hub, 2009.

[5] S.W. Souci, W. Fachmann, H. Kraut, Food Composition and Nutrition Tables, 1986/87, $3^{\text {rd }}$ Edition, Wissenschaftliche Verlagsgesellschaft, Stuttgart.

[6] A. Roulin, C. Chaparro, E. Piegu, S.Jackson, O. Panaud, Paleogenomic analysis of the short arm of chromosome 3 reveals the history of the African and Asian Progenitors of Cultivated rices, Genome Biology and Evolution, 2, 2010, 132-139.

[7] Anonymous, International year of rice, Rice and Human Nutrition, 2004.

[8] Chang, Te-Tze, "II. A.7 Rice" In: The Cambridge World History of Food. Cambridge University,2000.

[9] N. Khatoon, J. Prakash, Nutritional quality of microwave and pressure cooked rice (Oriza sativa) varieties, Food Science and Technology International 12(4), 2006, 297-305.

[10] D.F. Houston, Rice bran and polish in Rice: Chemistry and Technology Chouston, D.F.E.Ed. AACC Publications, Minnestoa, 1972, 272-300.

[11] B.S. Luh, S. Barbar, B.C. Benedito de, Rice bran's In: Chemistry and Technology, Rice production and utilisation, Van Nostrand Keinhold publications, 2(2), 1991, 313-362.

[12] N.F. Haard, S.A. Odunfa, C. Lee, R. Quintero-Ramirez, A. Lorence-Quinones and C. Wacher-Radarte, Fermented cereals: A global perspective, FAO Agricultural Services Bulletin, Chapter 1, 1999.

[13] International Rice Commission, Rice is life, International year of rice 2004 and its implementations, International rice commission food and Agricultural Organisation of the United Nations, Rome, Italy, 2004, 59.

[14] B.O. Juliano, D.B. Bechtel, The rice grain and its gross composition, In: Rice chemistry and Technology, St.paul, MN, USA, 2, $1985,17-57$.

[15] K. Ramaiah and M.V.B.N. Rao, Rice breeding and genetics, ICAR science monograph 19, Indian Council of Agricultural Research, New Delhi, India, 1953.

[16] M.A. Rood, Red Menace, Rice Journal 103, 2000, 18-20.

[17] P. Lambert, N.L. Saleh, R. Meullenet, Journal of studies on rice cooking, 2007, 82.

[18] F. Guarner, G.J. Schaafsma, Probiotics, International Journal of Food microbiology, 39, 1998, 237-238.

[19] G. Perdigon, S. Alvarez, probiotics and the immune State, In: Probiotics: The scientific basis Chapman and Hall, London, 1992, $145-180$.

[20] G.R. Gibson, M.B. Roberfroid, Dietary modulation of the human colonic micro organisms: Introducing the concept of probiotics, Journal of Nutrition, 125, 1995, 1401-1412.

[21] FAO- Food and Agriculture Organisation, Rice and human nutrition, International year of rice 2004, FAO, Rome, Italy, 2004.

[22] G.R. Gibson, Dietary modulation of human gut microflora using probiotics, British Journal of Nutrition, 80, 1998, $209-212$.

[23] P. Kontula, Von Wright, Oat bran beta-gluco-and Xylo oligosaccharides and fermentative substrates for Lactic acid bacteria, International journal of Food Microbiology, 45, 1998, 163-1699.

[24] P. Kontula, J. Jaskari, L. Nollet, I. De Smet, Von Wright and K. Poutanen, The colonisation of a stimulator of the human intestinal microbial ecosystem by a probiotic strain fed on a fermented oat bran product: effects on the gastrointestinal micro organisms, Applied Microbiology and Biotechnology, 50, 1998, 246-252.

[25] N.M. Delzenne, M.B. Roberfroid, Physiological effects of non-digestible oligosaccharides, Lebebsmittel - Wissenschaft and Technologies, 27, 1-6. 